UNIVERSITY OF CHITRAL JOURNAL OF LINGUISTICS AND LITERATURE

VOL. 3 | ISSUE I | JAN - JUNE | 2019

ISSN (E): 2663-1512, ISSN (P): 2617-3611

\title{
New World Order: Basra: A New Dawn in Electronic Literature
}

Rabia Aamir

Assistant Professor, Department of English, National University of Modern Languages, Islamabad, Pakistan

Research Fellowship Columbia University, New York, USA

"Objects and events are not primitive experiences. Objects and events are representations of relations. " (Baldwin, The Nihilanth: Immersivity in a First-

Person Gaming Mod 1)

\begin{abstract}
In this age of techno globalization "contemporary artists, poets, and musicians [are] making imaginative use of algorithms to generate new works and taking advantage of communications networks to craft cyber textual projects or works in cross-media formats" (Burdick 8). It is one of these cyber textual projects and a cross media format that this article takes as case study to explore. Titled "New World Order: Basra"i by Sandy Baldwin, this cyber textual project integrates, apparently, two very different genres of expression, i.e. a poem and a typical game of shooting and hunting. The visual analysis of the electronic digital narrative titled "New World Order: Basra" by Sandy Baldwin entails different steps for this visual analysis; namely composition interpretation, Semiology, and Discourse Analysis, discussed here shortly.

Keywords: Digital Humanities, cyber textual project, visual analysis, digital narrative, electronic literature
\end{abstract}

Humanity is living in an inescapable reality in the $21^{\text {st }}$ century. This reality is an ever changing phenomenon going around us. It is continuously changing our modes of perceptions towards almost everything. One such reality is the virtual field of digital humanities which can be considered a giant leap in the cognitive capacities of human knowledge, skills and endeavors stretched across from the last two decades of the previous century until the present times. The narratives which were earlier engaging the reader from the printed pages took on to newer dimensions. The virtual world of the digital world has become a thriving reality and " $[\mathrm{b}] \mathrm{y}$ their hierarchy, arrangement, organization, and other features they contribute to the production of the narrative in substantive ways" (Drucker 1). There have been precedents of visual mediums, means and methods of interpreting and telling in the discipline of humanities which were "the traditional domain of anthropologists and have only relatively recently re-emerged as popular among sociologists as well as applied social researchers working in areas such as education, social policy and social work" (Wiles 4). Digital humanities is extending this mode of human perception to new boundaries.

Electronic literature extending the modes of human experience from digitized texts (a scanned book etc.), manifests, at times, in the digital narratives of Graphic Novels, GN, or Digital Graphic 
Novel, DGN, with its most important aspect of visual and extra textual elements. The visual and extra textual elements are being used in different ways and capacities in order to enhance the cognition and modes of perception. At other times this feature of extra textual essentials is taking a phenomenal dimension of Artificial Intelligence, AI, a very recent development in the field of digital visual culture. For instance, in Electronic Literature Collection Vol 2 "Facade" is a form of electronic literary game in which the producers of this game Michael Mateas and Andrew Stern, set up a home with a husband and wife, both programmed with artificial intelligence. The third important character of this dramatic game is the player/ consumer. Both the husband and wife are shown to be going about their routine life when the player is going to interact with them. If this interaction is done in a congenial atmosphere the reaction of the two on screen players remain quite friendly but if the off screen player/ consumer uses any of the dialogues of the husband and wife to trigger or instigate a slightly heated discussion they may react in very different ways and at times it may be seen that the husband and wife of the game may take the situation of their heated debate to such a juncture that it becomes difficult for the player to handle these two characters with artificial intelligence (Mateas). A similar yet different game concerning the basics of artificial intelligence is the game of "Still Standing" (Nadeau). In this game the words of a poem are thrown across a virtual projector screen and they keep on moving in a random manner until the player/ consumer keeps on walking in front of the screen. As soon as the player stands motionless in front of the screen the words on the screen arrange themselves according to the silhouette of the player who may then read through the text of the poem etc., whatever the words arrange themselves into (Nadeau). This interesting poem makes the player/ consumer to exercise two skills at the same time of standing still and then reading with concentration across the text thus provided. It can be made an interesting exercise for young children to polish their skills of standing still and reading with concentration. Another use of these visual and extra textual elements are being used in computer forensics [see (Kirtz)] or "digital poem, retro-game, an anti-design statement and a personal exploration of the artist's changing worldview lens" (Nelson). Yet another example is that of an innovative experimentation with the reader using the hypertext, as can be seen from the interactive literature, "Deep Surface" [which] is based on a simple-minded metaphor: what if the pages of a book -- or more accurately, the SO-CALLED PAGES OF THE WEB - [sic] were made from some pliable fluid, like water, so that we could dive gradually from one plane of presentation to the next? (Moulthrop). Similarly, "Pieces of Herself" is an exploration of feminine embodiment and identity in relationship to public and private space. Using a drag-and-drop game interface, viewers scroll through familiar environments (e.g., domestic, outdoor, work) to collect metaphorical 'pieces' of the self and arrange them in compositions inside the body" (Davies). It may be seen from all the examples cited above that how the different manifestations of interactive digital literature are opening up new vistas of cognition and understanding in a user friendly digital narratives/ text/ visuals.

The world of virtual reality spans across many other forms of interactive literature/ drama or cinema like science fictions and speculative fiction produced by the writer of seminal works in this 
genre, William Gibson. His sprawl triology, also known as the Neuromancer (1984), Cyberspace (1986), or Matrix (1988) trilogy are some seminal works in this genre. Some writers like Larissa Lai are writing novels "[f]ramed by a playful sense of magical realism, Salt Fish Girl reveals a futuristic Pacific Northwest where corporations govern cities, factory workers are cybernetically engineered" (Lai). Though the cyberspace, cybernetics and science fiction genre are quite engaging fields of enquiry, this research is delimited to the in depth analysis of one production of electronic interactive literature, "New World Order Basra" by Sandy Baldwin to study the mores and tropes produced by such interactive literature.

According to one scholar in the book, Digital Arts \& Humanities: Scholarly Reflections (2012) "the first decade [of the twenty first century] is an amalgamation of old and new ideas being brought to the public and laid on their lap" (Young 23). This is what can be seen in the visual culture -hyper reality of the game under study. "New World Order: Basra" is explained as a modification for the game Half-Life by the author/ producer of this virtual realm. It may be taken as a manifestation of a kind which, stated in another context can be expressed as "The Development of New Media Models for Social Change" (Jakubowicz n.pag.). Professor Sandy Baldwin, the originator of "New World Order: Basra" says that "[a]s otherness invades, even the rocks and walls become alien, tables turn organic. Half-Life is a shooter game and the story advances through annihilation of the enemy" (Baldwin, The Nihilanth: Immersivity in a First-Person Gaming Mod 4). Therefore modeled on the usual game of shooting and killing the enemy like the game HalfLife; "New World Order: Basra" makes use of the typical weapons of a crowbar and a shotgun to destroy not the "Other" (Ashcroft 169) or any enemy but the words of apparently very simple but a very allegorical poem "Introduction to Poetry"ii (1988) by the American poet Laureate, Billy Collins.

Drawing interstitially from four different theoretical modes of inquiry this research paper about this interactive literature titled "New World Order: Basra" studies the impact such apposition of a poem and a video game has on the consumer of this virtual realm. Using Professor Espen Aarseth's model of Ergodic literature as the base line model of inquiry which is defined by Aarseth as nontrivial effort required to allow the reader to traverse through the text (Koskimaa), the other tools thus used are evenly balanced between two traditional and two innovative modes. The two relatively new modes of inquiry being visual analysis and visual rhetoric analysis; where the discourse analysis and discourse analysis with particular regards to post colonialism being a relatively traditional modes of exploration. The rationale for such a mode of investigation is drawn from a study conducted in an MIT conference back in 1999. Professor Andrew Jakubowicz, in a conference in 1999 talked in terms of documentary but it is something relevant for this paper too when he said that "Documentary is facing dramatic changes as the new media open up issues of complexity and diversity not available to traditional single media forms.... [and by bringing] together cyber space and cultural conflict, we can begin to see a point of intersection where communities can take greater control of the representation of their own histories, and in so doing, move towards a future which is infused with a greater awareness of the necessity but also the 
fragility of cultural collaboration" (Jakubowicz n.pag.). Since the sample interactive literature of "New World Order: Basra" is an interplay of cyber space, textuality, visual sequences and political reality this research paper examines their mutual interaction and the subsequent impact on the consumer of this genre.

This research paper targets three key questions in order to establish the significance of this mode of interactive literature and draws on its relevant impact in the contemporary world.

1. How does the text of the poem integrated in cybertext of this game a product of the historical period in which it is written?

2. What is the significance of juxtaposition of the text of the poem "Introduction to Poetry" (1988) and the game, "New World Order: Basra"?

3. How and why do the social economic and political changes contribute for the Capitalism to reify people into things?

Answers to all these three research questions will be illustrated with the relevant modes of inquiry suitable to the question thus posed. In other words, a question may be answered by one or two or all theoretical modes of visual or visual rhetoric analysis and discourse analysis with relevant features of postcolonialism as manifested in this interactive literature. For ready reference and convenience the visual model for Ergodic Literature, as presented by Professor of Digital Culture at the university of Jyvaskyla, Finland, Raine Koskimaa, in his PhD dissertation Digital Literature: From Text to Hypertext and Beyond (2000) is given as under:

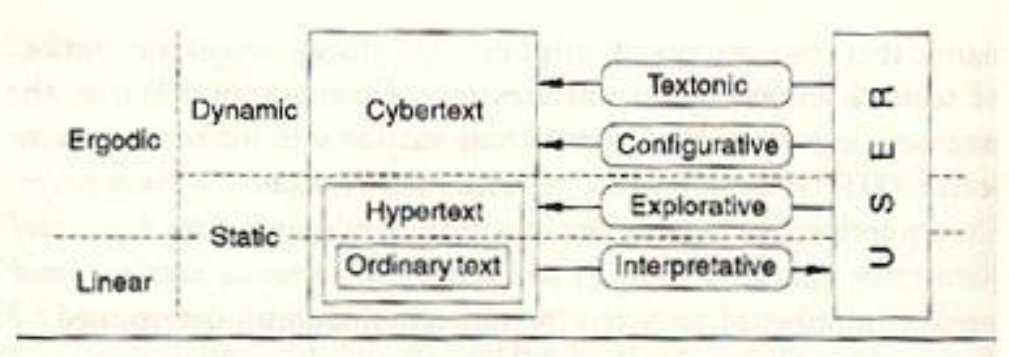

It may be seen from this figure that the sample of interactive literature of "New World Order: Basra" under study is a form of Ergodic literature which is dynamic versus the static linear literature. Additionally it may be seen that ergodic literature is a cyber-text which uses the features of exploration, configuration and textons (the building blocks of a text) which are experienced by the user. Where, the ordinary linear text is received as traditionally interpretative reality by the user.

This at length discussion about the theoretical framework used in this study impels the discussion towards the answer to our first research question; that how the text of the poem integrated in cybertext of this game being a product of the historical period in which it was written. The poem "Introduction to Poetry" was written in 1988 by Billy Collins, Poet Laureate of United States of America from 2000-2003. The main theme of the poem is about letting the poem be and enjoying 
the poem with its original texture and the meaning it gives of its own accord rather that whittling the meaning out of the poem with harsh actions. One possible interpretation of the poem may be that the paraphrasing exercise that is ordinarily used for understanding a poem is something which should be avoided as per the idea given by the poet, Billy Collins.

However, Sally Baldwin has used the textons of this poem and embroidered them into the game of Half Life in which the consumer is supposed to shoot down the enemy which are the words of the text of this poem. This points to a very pertinent historical event which took place in 2003, i.e. the invasion of Iraq. When the "[h] istorical situatedness, historical embedment, and the politics of [this] literary text[]" (Bertens 61) of this poem is analyzed it becomes quite apparent that the progenitor of this interactive literature, "New World Order: Basra" is building an analogy between the text of the poem and the extended metaphor of the event of invasion of Iraq. It is the year 2003 which marks for the initiation of the event and the production of this game and " $[\mathrm{t}] \mathrm{he}$ result is a text-length trope which preserves the two-level ontological structure of metaphor (literal frame of reference and metaphorical frame of reference), but in which, instead of being announced explicitly, the two-level structure remains implicit, disseminated throughout the text" (McHale 140). Though, in this quote, Brian McHale is talking in terms of written texts in his book Postmodernist Fiction (1987) but it can be appropriated on this interactive literature of Sandy Baldwin. In "New World Order: Basra" he has countered all sorts of literature and war mongering frenzy that was being generated in the media and the press during the invasion. By juxtaposing the two things he has negated the uncalled for hype created in the mass media culture. It can therefore be said that his poetical use of the text of the poem, integrated in cyber text of this game makes it a product of the historical period in which it was written and certainly not without reason.

For addressing the second question of the significance of juxtaposition of the text of the poem "Introduction to Poetry" (1988) and the game, "New World Order: Basra" (2003) a sidelight on the originator of this interactive literature, Sandy Baldwin, would be of avail. Sandy Baldwin is Associate Professor of English and Director of the Center for Literary Computing at West Virginia University. He received his PhD from New York University and is a Fulbright Scholar. His work imagines the future of literary studies in a digital age. $\mathrm{He}$ is on the Electronic Literature Organization's Board of Directors, where he serves as the ELO Treasurer, and is Executive Editor at Electronic Book Review.

This insight into the background of the producer of this interactive literature sheds light on the basic idea behind this creation. It may be seen clearly that though the producer may not have over emphasized it but there is a grand idea working behind this production - the idea which exposes the lies told all across media; lies regarding the then regime of Saddam Hussain hiding the weapons of mass destruction. In their article, "Visual Rhetoric: Analyzing Visual Documents" the writers have discussed "[a] rhetorical situation [which] occurs when an author, an audience and a context come together and a persuasive message is communicated through a medium" (Mark Pepper 2). It may be seen that Sandy Baldwin has put across a very important message to the "target audience..[who are always]... seeking and speculating..." (Mark Pepper 2-3). Alternatively it may 
be understood that visual rhetoric analysis which focusses on the purpose as being informational, inspirational and motivational may be seen as working through this interactive literature, especially the purpose of inspiration and motivation. This production by Sandy Baldwin is inspirational as it is clearly evoking emotions with the color symbolism, an integral part of this visual rhetoric analysis, which is being used to explain the creation of mood and feeling by the writer. It is also motivational as it initiates and spurs action, attendance and participation.

In the second stage of visual rhetoric analysis in terms of context this essay of this mode of analysis given at the website of Welcome to the Purdue OWL present the basic consideration of the use of any techniques to draw attention in a potentially busy or competitive environment (Mark Pepper 4). With this in view it may be seen that Sandy Baldwin has made effective use of the context of this poem and the event of invasion of Iraq of 2003. And as asserted in the book, Digital Text: From Text to Hypertext and Beyond (2000), "it was quite natural that along the shoot'em ups and other action games, also text based games were developed (Koskimaa). "New World Order: Basra" (2003) is a clear indication of such an effort by Sandy Baldwin and quite a good one.

Building the critique further upon the lines of the first feature of the visual analysis, the composition interpretation; it is seen that it renders that the background and the foreground of this 3D game of "New World Order: Basra" has a color scheme of sepia colors. The earthly tones of the combination of these colors in their light and dark hues lend a somber and dignified ambiance to the game. The floor, dark brown with occasional patches of mahogany and the ceiling with a regular pattern of straight lines of the same color as the floor, combined with its pastel beige background makes it blend comfortably with the walls of cubicle hall, with creamy beige walls, in which the whole action takes place. The hall is strewn by an array of, not enemies as the usual game of Half-Life, but the random words of the poem "Introduction to Poetry" (1988). The player is made to hunt down the hanging wooden planks with the words of this poem written across them with either a crowbar or a shotgun.

The consequentionalist approach (Wiles 7) as mentioned in Visual Ethics: Ethical Issues in Visual Research (2008) is also made use of while doing this analysis. The consequentionalist approach believes that "ethical decisions should be based on the consequences of specific actions so that an action is morally right if it will produce the greatest balance of good over evil. [This approach also emphasizes the fact that a]ll individuals have a moral outlook about what is right and wrong that guides their behaviour" (Wiles 6). Applying this approach it may be seen that the sequence of this arrangement in this game can be further understood with the second step of visual analysis i.e Semiology.

Analyzing in a classic Saussurean fashion, the signifier and the signified may have any or all of the iconic, indexical or symbolic representations. The crowbar and the shotgun, the weapons in the hands of the player signify an iconic representation as these weapons are used for attack, both in the real world and the virtual world of this digital game narrative. In the indexical stage of the semiological analysis it may be seen that the world is encapsulated in the four walls of the hall where the whole action is taking place. It is in the symbolic stage of analysis that it may be seen 
that the additional relationships get manifested when seen in the sociopolitical and cultural perspectives. The symbolical imagery of the poem can help understand the signified meaning of the game as a whole. Though the producer of this game Sandy Baldwin has explained it in the paradigm of immersion of the player into a video game when he says that the "dimensionality and solidity of the words come[] to symbolize 'reading.' Immersion in this environment is reading" (Baldwin, The Nihilanth: Immersivity in a First-Person Gaming Mod 2), there may be some extended metaphorical understanding that may be rendered to this digital narrative beyond the phenomenon of immersion as discussed by the author. The symbolic representation of this unique combination of the poem whose main theme signify that a poem should only be left alone to be, and not be tortured to whittle/force the meaning out of it. Collins expresses this in the poem by saying, "t[ying] the poem to a chair with rope/ and tortur[ing] a confession out of it" (Collins 1 1314). When these words are juxtaposed in this game, it condenses it into a totally new set of meanings. The poem by Billy Collins evokes an imagery where one can "[i]magine a bungee cord on the surface of the water and someone (with the rope stretched) diving from high above, and reach the bottom of the water, look around and collect the meaning, and jump right back to the surface" (Pozzi). Alternatively the imagery of holding "up of a poem up to the light/ like a color slide" (Collins 12-3) means that the poet is asking the reader to delve into the real essence of the poem by holding it up to a light in order to see and appreciate its colors and depth.

This unique metonymical symbolism of the poem integrated into the game of "New World Order: Basra" takes the discussion to the next level of interpretation using Discourse Analysis. In answering the final research question of how and why do the social economic and political changes contribute for the Capitalism to reify people into things? As, to the 'how' part of this question i.e. how does the social economic and political changes contribute for the Capitalism to reify people into things, the specific image of the words hanging as wooden planks in the environment of the sepia colored hall where they are being shot down at random is helpful. It solidifies an understanding of the whole scenario. It suggests that the images of this game construct the world view of Basra, which, to put it synecdochicallly, is being shot down in order to create a new world order just as the suggested poem is being tortured to force out its meanings in the poem by Billy Collins.

As to the 'why' part of the question, that why does the social economic and political changes contribute for the Capitalism to reify people into things we need to take the discussion on the second level of Discourse Analysis of this game "New World Order: Basra". According to the article by Sandy Baldwin titled the same as the game itself, i.e. "New World Order: Basra" the "thematic violence in Collins' poem resonated through the creation of NWO in early 2003, during the second invasion of Iraq" (Baldwin, New World Order: Basra). Interpreting this game in an institutionalized perspective, it is deduced that the standpoint of postcolonial theory can be seen as working through the binaries thus created both in the actual poem of Billy Collins and the game. In "Introduction to Poetry" (1988) the binary is created between the reader and the labored meaning of any poem, while in this game, "New World Order: Basra", the binaries are between the 
hegemonic stance of the player of the game and the oppressed words on wooden planks that are being brutally massacred just as the actual war imposed on Iraq in 2003.

A war, which abrogated and marginalized the habitat of this city and was appropriated with Coalition Provisional Authority which was established as a transitional government of Iraq following the invasion of Iraq on 19 March 2003 by the United States, United Kingdom, Australia and Poland. This is the hegemony against which Sandy Baldwin has produced the rhetoric of this game which signifies that '[ $\mathrm{t}]$ he colonizer's discourse, his most effective weapon in the cultural encounter, is less stable and secure than he thinks. One reason is that stereotyping is a basic element of colonial discourse" (Bertens 167). This colonialist rhetoric is endemic to the autocratic regimes and goes on to reveal "how they attain their coherence by setting up false oppositions between a supposed centre and an equally fictive margin and how their language invariably deconstructs the coherence they try to establish" (Bertens 171). The interactive literatures like "New World order Basra" is a clear indication that such hegemonies are disrupting the peaceful milieu of this planet, are trying to sabotage the existence of ancient cities like Basra, and presenting a hegemonic rhetoric which is actually deconstructing the coherence in their language that they are trying to project.

\section{Conclusion}

This research paper has highlighted a new understanding of hegemony in the context of electronic literature. Sandy Baldwin has dexterously made use of literature (Billy Collins' poem 'Introduction to Poetry') and digital games (Half Life, a typical game of shooting and hunting) to present a new reality in the field of digital humanities. With the help of the theoretical tools of inquiry, I have tried to bring forth Baldwin's projection of the hegemonic design of creating a new world order with its usual subversive results. The crushing of the indigenous peoples of Basra and Iraq with an iron fist of hegemonic design has resulted in an anti-colonial political struggle of its people against the oppressors. If Capitalism is reifying and commodifying people into things (Bertens 65) then the game, "New World Order: Basra", by Sandy Baldwin, can be taken as a symbolic, metonymical

and metaphoric representation of this hegemony in a visual narrative of literature which has furthered the comprehensive boundaries of digital humanities. 
Works Cited

Ashcroft, Bill., Garreth Griffiths and Helen Tiffin, ed. Key Concepts in Post Colonial Studies. London and New York: Routledge, 1998. Print.

Baldwin, Sandy. "New World Order: Basra." 2003. Electronic Literature Collection Vol 2. Web. 19 March 2016. <http://collection.eliterature.org/2/works/baldwin_basra.html>.

-. The Nihilanth: Immersivity in a First-Person Gaming Mod. West Virginia University, n.d. Web.

—. "The Nihilanth: Immersivity in a First-Person Gaming Mod." 2014. New World Order: Basra. Web. 19 March 2016. <http://collection.eliterature.org/2/works/00_baldwin.html>.

Bertens, Hans. Literary Theory, The Basic Theory. New York: Routledge, 2008. Print.

Burdick, Anne. Johanna Drucker and Peter Lunenfeld. Digital Humanities. CAMBRIDGE, MASSACHUSETTS LONDON, ENGLAND: Massachusetts Institute of Technology, 2012. Web. 2342016.

Collins, Billy. "Introduction to Poetry." The Apple that Astonished Paris. University of Arkansas Press, 1988, $\quad$ 1996. Web. $19 \quad$ March 2016. <http://www.poetryfoundation.org/poem/176056>.

Davies, Juliet. "Pieces of Herself." n.d. Electronic Literature Collection Vol 2. Web. 21 May 2016. <http://collection.eliterature.org/2/works/davis_pieces_of_herself.html>.

Drucker, Johanna. "Graphic Devices: Narration and Navigation." Narrative 16.2 (2008): 121-139. Web. 26 May 2019. <https://www.jstor.org/stable/30219279>.

Jakubowicz, Andrew. "Discourses of the Social Making Multicultural Australia - A Multimedia Documentary"." Media in Transition Conference at MIT on October 8, 1999.]. Australia: University of Technology, Sydney, Australia, 1999. n.pag. Web. 20 May 2016. <http://web.mit.edu/m-i-t/articles/index_jakubowicz.html>.

Kirtz, Jamie Lee. "Computers, Comics and Cult Status: A Forensics of Digital Graphic Novel." DHQ: Digital Humanities Quarterly 8.3 (2014): 1-14. Web. 19 March 2016. <https://www.researchgate.net/publication/301651158_Kirtz_J_2014_Computers_Comic s_and_Cult_Status_A_Forensics_of_Digital_Graphic_Novel_Digital_Humanities_Quarte rly_83>.

Koskimaa, Raine. Digital Literarature: From Text to Hypertext and Beyond. 2000. Web. 4 April 2016. <http://users.jyu.fi/ koskimaa/thesis/thesis.shtml>.

Lai, Larissa. "Salt Fish Girl." 4 Aug 2002. Goodreads. Web. 20 May 2016. <https://www.goodreads.com/book/show/531944.Salt_Fish_Girl>.

Mark Pepper, Allan Brizee, Elizabeth Angelli. "Visual Rhetoric: Analysing Visual Documents." n.d. Welcome to the Purdue OWL. Web. 14 March 2016.

Mateas, Michael. and Andrew Stern. "Facade." 2005. Electronic Literature Collection Vol 2. Web. 19 March 2016. <http://collection.eliterature.org/2/works/mateas_facade.html>.

McHale, Brian. Postmodenist Fiction. London and New York: Routledge: Taylor and Francis, 1987, 2004. Print. 
Moulthrop, Stuart. "Deep Surface." n.d. Electronic Literature Collection Vol 2. Web. 18 March 2016. 〈http://collection.eliterature.org/2/works/moulthrop_deepsurface.html>.

Nadeau, Bruno. and Jason Lewis. "Still Standing." 2005. Electronic Literature Collection Vol 2. Web. $19 \quad$ March 2016. <http://collection.eliterature.org/2/works/nadeau_stillstanding.html>.

Nelson, Jason. "Game, Game, Game and Again Game." 2007. Electronic Literature Collection Vol 2. Web. 19 March 2016. <http://collection.eliterature.org/2/works/nelson_game.html>.

Pozzi, Gerard. "'Introduction to Poetry" - Analysis." 19 Jan 2012. The Books Nest. Web. 19 March 2016. <https://thebooknest.wordpress.com/2012/01/19/introduction-to-poetry-analysis/>.

Wiles, Rose., Jon Prosse2, Anna Bagnoli, Andrew Clark, Katherine Davies, Sally Holland, Emma Renold. "Visual Ethics: Ethical Issues in Visual Research." ESRC National Centre for Research Methods Oct 2008. Web. 26 May 2019. <http://eprints.ncrm.ac.uk/421/1/MethodsReviewPaperNCRM-011.pdf〉.

Young, Gareth. "Twenty-first Century Music Technology." Digital Arts \& Humanities: Scholarly Reflections. University College Cork, 2012. 20-24. Web. 19 March 2016. $<$ http://josullivan.org/wpcontent/uploads/Digital-Arts-Humanities ScholarlyReflections.pdf>.

\section{${ }^{\mathrm{i}}$ Appendix II}

"New World Order: Basra” by Sandy Baldwin

http://nt2.uqam.ca/en/repertoire/new-world-order-basra

http://collection.eliterature.org/2/works/00_baldwin.html

\section{ii Appendix I}

From: https://www.poetryfoundation.org/poems/46712/introduction-to-poetry

\section{Introduction to Poetry}

BY BILLY COLLINS

I ask them to take a poem

And hold it up to the light

Like a color slide

Or press an ear against its hive.

I say drop a mouse into a poem

and watch him probe his way out, or walk inside the poem's room

And feel the walls for a light switch.

I want them to waterski 
across the surface of a poem

Waving at the author's name on the shore.

But all they want to do

Is tie the poem to a chair with rope

And torture a confession out of it.

They begin beating it with a hose

To find out what it really means.

Billy Collins, "Introduction to Poetry" from The Apple that Astonished Paris. Copyright 1988, 1996 by Billy Collins. Reprinted with the permission of the University of Arkansas Press.

Source: The Apple that Astonished Paris (University of Arkansas Press, 1996)

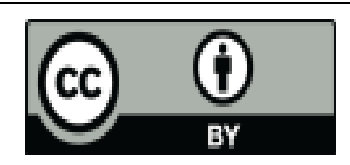

@ 2017 by the author. Licensee University of Chitral, Journal of Linguistics \& Literature, Pakistan. This article is an open access article distributed under the terms and conditions of the Creative Commons Attribution (CC BY) (http://creativecommons.org/licenses/by/4.0/). 